\title{
SEEPAGE FLOW DYNAMICS IN A NEGATIVE PRESSURE DIFFERENCE IRRIGATION SYSTEM
}

\author{
S. M. MONIRUZZAMAN 1 , Teruyuki FUKUHARA², Masaki ITO3 \\ and Yoshihiro ISHII 4 \\ 1 Student Member of JSCE, PhD Scholar, Dept. of Architecture and Civil Engineering, \\ University of Fukui (3-9-1 Bunkyo, Fukui 910-8507, Japan) \\ 2 Member of JSCE, Dr. of Eng., Professor, Dept. of Architecture and Civil Engineering, \\ University of Fukui (3-9-1 Bunkyo, Fukui 910-8507, Japan) \\ ${ }^{3}$ Member of JSCE, Civil Engineer, Kinki Construction Association \\ (506-2 Hojo, Himeji-shi, Hyogo 670-0947, Japan). \\ ${ }^{4}$ Member of JSCE, Dr. of Eng., Associate Professor, Dept. of Civil Engineering and Urban Design, \\ Hiroshima Institute of Technology (2-1-1 Miyake, Saeki-ku, Hiroshima 731-5193, Japan)
}

\begin{abstract}
This study proposes a theoretical model to predict soil wetting pattern and water balance in a negative pressure difference irrigation (NPDI) system and describes laboratory experimental results from which this model was derived. The experiments were conducted by using a porous pipe, a water reservoir and a soil column filled with Kawanishi sand. The temporal variations in volumetric water content profile, supplied water, soil water storage and evaporation were calculated by the proposed model. The calculated results were in good agreement with the experimental results. The margin of error of the water balance was in the range of 3 to $7 \%$. It is concluded that the proposed model is valid for an optimal design of the NPDI system.
\end{abstract}

Key Words: subsurface irrigation, model, numerical simulation, volumetric water content, water balance

\section{INTRODUCTION}

Negative pressure difference irrigation (NPDI) system is a kind of subsurface irrigation and is composed of a water reservoir and a porous pipe installed in soil. The water reservoir is placed at a lower elevation than the porous pipe to generate negative pressure, $P_{n}$, shown in Fig. 1. Water moves toward the porous pipe from the reservoir in a water supply conduit linking these two when the absolute value of the soil water matric potential, $|\psi|$, is larger than the absolute value of $P_{n},\left|P_{n}\right|$. The supplied water per unit time (supplied water rate) is in proportion to the negative pressure difference (NPD), $|\psi|-\left|P_{n}\right|$. Saving water can be enhanced by the NPD because the supplied water rate, which is in proportion to the NPD, lessens or becomes zero automatically as the wetting process of the soil progresses. Yabe et al. ${ }^{1)}$ showed that water wasted in the NPDI is less than that of the drip irrigation.

A numerical simulation is useful to predict the soil water storage (SWS), supplied water (SW) and evaporation (EV) associated with the change in $P_{n}$ and the installation depth of a porous pipe. Especially the spread of the wetted soil zone affects the water loss due to evaporation from the soil surface and deep percolation beyond the root zone. An experimental approach will require a lot of work and time to understand seepage flow dynamics of the NPDI. Therefore, a theoretical approach will be a powerful support tool for designing an optimal subsurface irrigation management system by using a porous pipe. However, little numerical information about the NPDI is available for the relation between $P_{n}$ and the SW or SWS.

Theoretical studies on the NPDI system may be divided into two categories according to the installation direction of the porous pipe, i.e. horizontal and vertical installation. Most of the past studies focused on the seepage flow around a porous pipe installed in soil horizontally. For example, Kato et al. ${ }^{2}$ simulated a $\psi$ profile by conformal mapping. The evaporation acted as a sink for soil moisture reduction. Tanigawa et al. ${ }^{3)}$ made a comparison of 
their prediction and observation about $\psi$ profile. The model calculation showed good agreement with the observed $\psi$ profiles. The evaporation flux was given as a boundary condition (known) on the soil surface. Ashrafi et al. ${ }^{4}$ simulated the change in the wetting front due to the horizontal spacing, installation depth and hydraulic conductivity of the porous pipe. Siyal et al. ${ }^{5)}$ simulated the wetting front and volumetric water content, $\theta$, profile around a porous pipe and investigated relations among the hydraulic and physical parameters of the soil and the wetting front.

On the other hand, the study of the seepage flow of vertically installed porous pipe has been limited. Peifu et al. ${ }^{6)}$ quantified the temporal horizontal and vertical spreads of the wetted soil. The maximum wetted expansion was predicted by a statistical analysis. Akhoond et al. ${ }^{7)}$ developed empirical equations to calculate the wetting front configuration for three different lengths of the porous pipe.

It was common in these past studies that the validity and reliability of the seepage model had not been fully secured. The formulation of evaporation was insufficient in these past studies. We have to assess whether a simulation model not only reproduces the wetting front configuration or soil moisture content profile but also satisfies the water balance of the irrigation system. The water balance is essential for an optimal design and management of the subsurface irrigation.

In this study evaporation from the soil surface associated with the upward expansion of the wetted soil was taken into account theoretically and the validity of the proposed seepage model was verified by comparing the $\theta$ profile and water balance of the NPDI system.

\section{THEORIES OF NPDI}

\section{(1) Percolation theory}

The supplied water rate seeping out of a porous pipe, $M_{\text {hsup }}(\mathrm{kg} / \mathrm{hour})$, is calculated by the following equation:

$$
M_{\text {hsup }}=2 \pi R_{p} \rho_{w} \int_{-1 / 2}^{1 / 2} q_{r} d z
$$

where $q_{r}$ is the percolation flux in the radial $(r)$ direction (m/hour) (see Fig. 1), $R_{p}$ is the outer radius of porous pipe $(\mathrm{m}), \rho_{w}$ is the density of water $\left(\mathrm{kg} / \mathrm{m}^{3}\right), l$ is the length of the porous pipe $(\mathrm{m})$ and $z$ is the vertical coordinate $(\mathrm{m})$. In order to calculate $q_{r}$, it is an important question whether or not Darcy's law can be applied simply to water flow across a boundary between two different porous media (hereafter referred to as interface), i.e. the porous pipe and the surrounding soil as shown in Fig. 1. Taking account of the flow resistance of the interface, we attempted to apply Darcy's law to $q_{r}$ as follows:

$$
q_{r}=-c k_{p}\left[\frac{\psi-\left(P_{n}+z\right)}{t_{p}}\right]
$$

where $k_{p}$ is the saturated hydraulic conductivity of the porous pipe $\left(=2.30 \times 10^{-5} \mathrm{~m} / \mathrm{hour}\right), c$ is the interfacial resistance coefficient of percolation and $t_{p}$ is the thickness of the porous pipe (m).

When Eq. (2) is applied to air dried soil, $q_{r}$ could be expressed by replacing $\psi$ with the matric potential of the air dried soil, $\psi_{0}$ (= constant). Substituting Eq. (2) into Eq. (1) yields

$$
M_{\text {hsup }}=\frac{2 \pi R_{p} \rho_{w} c k_{p} l}{t_{p}}\left(P_{n}-\psi_{0}\right)
$$

Eq. (3) may be applicable to the water supply for a short period of time when the change of $\theta$ around the porous pipe is very small. It is found that $M_{h s u p}$ is in proportion to $\psi_{0}$. Once $\psi_{0}$ and $M_{h s u p}$ are known, $c$ can be calculated by Eq. (3).

\section{(2) Evaporation theory}

When the soil surface is wet, the cumulative evaporation may be written as follows:

$$
M_{\text {eva }}=\int m_{\text {heva }} A_{\text {wet }} d t
$$

where $M_{\text {eva }}$ is the cumulative evaporation ( $\left.\mathrm{kg}\right), m_{\text {heva }}$ is the evaporation mass flux $\left(\mathrm{kg} / \mathrm{m}^{2} / \mathrm{hour}\right), A_{\text {wet }}$ is the wetted surface area $\left(\mathrm{m}^{2}\right)$ and $t$ is time (hour). $m_{\text {heva }}$ can be given by the following equation developed by Futagami et al. ${ }^{8)}$ :

$$
m_{\text {heva }}=\beta \alpha_{v} D_{\text {atm }}\left(\rho_{v s}-\rho_{\text {vair }}\right)
$$

where $\alpha_{v}$ is the evaporation coefficient $\left(\mathrm{m}^{-1}\right), D_{a t m}$ is the diffusion coefficient of vapor in air $\left(\mathrm{m}^{2} /\right.$ hour $), \rho_{v s}$ is the vapor density on the soil surface $\left(\mathrm{kg} / \mathrm{m}^{3}\right), \rho_{\text {vair }}$ is the vapor density of air $\left(\mathrm{kg} / \mathrm{m}^{3}\right)$ and $\beta$ is the evaporation efficiency. $\beta$ is a function of the $\theta$ of the wetted soil surface layer. When $\theta \leq \theta_{c r}, \beta=0$ and when $\theta>\theta_{c r}, \beta \leq 1$. Here $\theta_{c r}$ (critical $\theta$ ) represents the threshold of $\theta$ that discriminates between wet and dry soil.

\section{(3) Mass balance equation \\ a) Total mass balance}

The water balance of the NPDI consists of the amount of the SW $\left(M_{\text {sup }}\right)$, the amount of the SWS $\left(M_{\text {soil }}\right)$ and the amount of the $\mathrm{EV}\left(M_{\text {eva }}\right)$, and is given by the following simple equation:

$$
M_{\text {sup }}=M_{\text {soil }}+M_{\text {eva }}
$$

\section{b) Mass balance in soil}

According to cylindrical coordinates, the mass conservation of seepage flow is given as:

$\rho_{w} C_{\alpha} \frac{\partial \psi}{\partial t}=\frac{1}{r} \frac{\partial}{\partial r}\left(r \rho_{w} k \frac{\partial \psi}{\partial r}\right)+\frac{\partial}{\partial z}\left\{\rho_{w} k\left(\frac{\partial \psi}{\partial z}+1\right)\right\}(7)$ where $C_{\alpha}$ is the specific moisture capacity and $k$ is 
the unsaturated hydraulic conductivity of soil. An explicit finite difference discretization method used by Fukuhara et al. ${ }^{9)}$ was applied to solve Eq. (7). The size of mesh and time increment used in this computation were $\Delta r=\Delta z=5 \mathrm{~mm}$ and $\Delta t=10$ seconds, respectively.

\section{c) Boundary and initial conditions}

The seepage flow is considered to be uniform in all radial directions. There is no water flux across the bottom of the porous pipe as well as all of the boundaries of the analytical domain except the soil surface. Initially the soil is in an air dried moisture condition.

\section{EXPERIMENTAL METHODS}

\section{(1) Water balance test}

Fig. 1 shows a schematic diagram of the experimental arrangement in a temperature and humidity controlled room $\left(25^{\circ} \mathrm{C}\right.$ and $30 \%$, respectively). A PVC pipe (diameter $=0.20 \mathrm{~m}$ and height $=0.21 \mathrm{~m}$ ) was composed of seven rings with a height of $0.03 \mathrm{~m}$ each and used as a soil column. The soil column was filled with Kawanishi sand with a bulk density of $1410 \mathrm{~kg} / \mathrm{m}^{3}$ and $\theta$ of 0.019 for all experimental cases. A porous pipe (length, $l=0.1$ $\mathrm{m}$, outer radius, $R_{p}=12.5 \mathrm{~mm}$ and thickness, $t_{\mathrm{p}}=6$ $\mathrm{mm}$ ) was installed vertically at the center of the soil column as shown in Fig. 1. A Marriott tube in a water supply tank was used to keep the $P_{n}$ constant. $P_{n}$ was defined as the difference in elevation between the water surface in the reservoir $(a-a)$ and intermediate elevation of the porous pipe (b-b) (see Fig. 1). A small pump was used to remove air bubbles in the water supply conduit. Two electric balances (minimum reading $0.1 \mathrm{~g}$ ) were placed separately to measure $M_{\text {sup }}$ and $M_{\text {soil }}$ simultaneously. All the data were downloaded into two computers in 60 minute intervals. $M_{e v a}$ was obtained by Eq. (6). A water balance test was carried out for two different experiment durations ( 24 and 72 hours) under $P_{n}=-$ $0.02 \mathrm{~m}$ and $-0.07 \mathrm{~m}$, respectively .

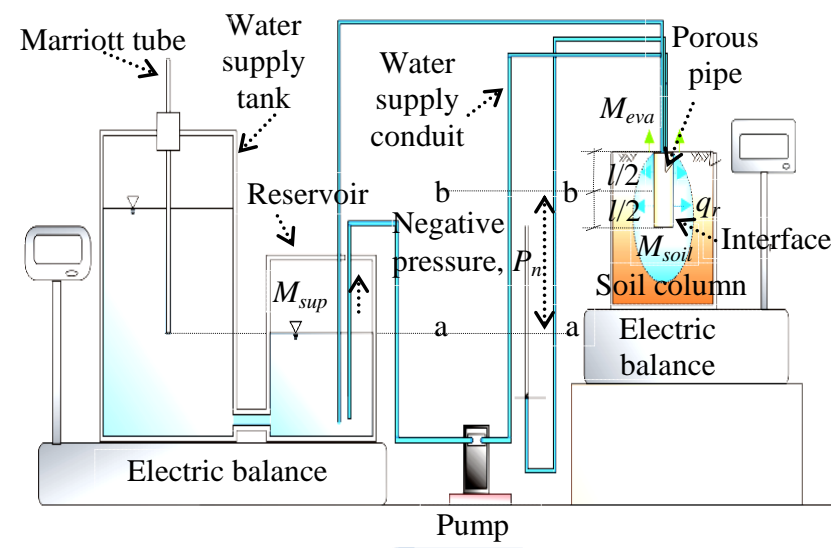

Fig. 1 An experimental setup for a water balance test

\section{(2) Wetting front and wetted surface area}

After the end of each water balance test, dry soil around the wetted soil was removed from the soil column and the wetting front was observed as shown in Fig. 2. The vertical and radial expansion of wetting front was measured with a scale. Pictures of the soil surface were used to measure the wetted soil surface area, $A_{\text {wet }}$, (see Fig. 2) at $t=20,40$ and 60 hours.

\section{(3) Volumetric water content}

The soil sampling for measuring the $\theta$ profile in the $r$ direction, $\theta(r)$, was carried out by the following process: (1) A thin plastic plate was horizontally inserted into a narrow space between the top two rings after cutting through the glue between the two rings with a knife. (2) Four round shape sheets with a height of $30 \mathrm{~mm}$ each were rolled into tubes of various radial distances from the porous pipe surface ranging from 10 to $60 \mathrm{~mm}$. These tubes were then pressed vertically into the soil to segment the soil concentrically as shown in Fig. 2. The soil samples between the tubes were then extracted. As a result four annular soil samples were taken at the width of 10 and $20 \mathrm{~mm}$ (inside two annuli were 10 $\mathrm{mm}$ and the rest were $20 \mathrm{~mm}$ ). (3) The $\theta(r)$ of the top soil layer was measured by the gravimetric soil sampling method. (4) The top ring was removed and then the above mentioned processes were repeated to obtain the $\theta(r)$ of the second, third $\cdots$ and bottom soil layers (30 mm each) in the same order (see Fig. 2).

\section{(4) Permeability and water retention}

The soil moisture characteristic curve was obtained by using a soil column method. A $0.7 \mathrm{~m}$ long column was assembled with 35 rings with a height of $20 \mathrm{~mm}$ and a diameter of $50 \mathrm{~mm}$ each. The column was filled with air dried Kawanishi sand. Water was introduced into the bottom of the column by a pipe from a reservoir. The water surface in the reservoir was maintained at the same level with the bottom of soil column throughout the experiment. Since water movement from reservoir to column was stopped naturally after three weeks, $\theta$ was considered to be in equilibrium state.

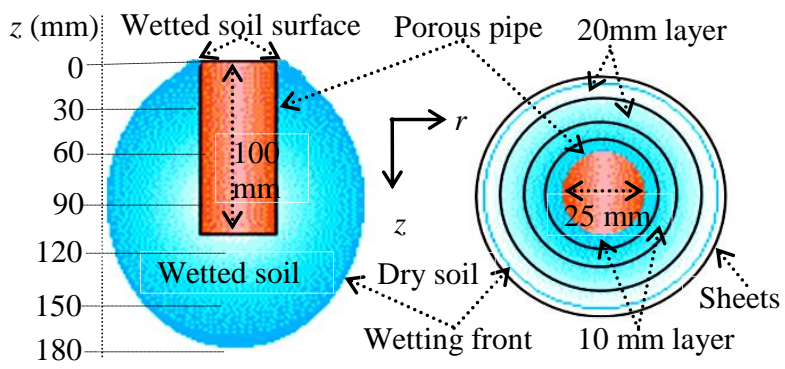

Fig. 2 Soil sampling in vertical and radial directions 
After that the soil column was disassembled to measure the relation between $\theta$ and the height of wetting front above the water surface in the column.

The saturated hydraulic conductivity of Kawanishi sand, $k_{s}$ was measured by the falling head method. The method used by Kono et al. ${ }^{10}$ was employed to obtain the $k-\theta$ relation.

\section{(5) Evaporability test}

An evaporability test to obtain $\alpha_{v}$ and $\beta$ in Eq. (5) was carried out according to the experimental method proposed by Futagami et al. ${ }^{8)}$. A soil ring with a thickness of $10 \mathrm{~mm}$ and a radius of $25 \mathrm{~mm}$ and an electric balance with a minimum reading of $0.001 \mathrm{~g}$ were used to measure $m_{\text {heva }}$ from the soil surface and $\theta$ in the ring.

\section{RESULTS AND DISCUSSIONS}

\section{(1) Properties of Kawanishi sand}

Fig. 3 shows the measured soil water retention curve and it is given by the van Genuchten's 11) equation:

$$
\theta=\theta_{r}+\frac{\theta_{s}-\theta_{r}}{\left[1+(\alpha|\psi|)^{n}\right]^{m}}
$$

where $\theta_{r}(=0.019)$ is the residual water content, $\theta_{s}(=$ $0.4)$ is the saturated water content, $\alpha$ is the scaling parameter $\left(=9 \mathrm{~m}^{-1}\right), n$ is the soil water characteristic curve index $(=18)$ and $m=1-1 / n$.

Fig. 4 shows the relation between the $k$ and $\theta$ and it follows the Brooks and Corey's ${ }^{12)}$ equation:

$$
k=k_{s}\left(\frac{\theta-\theta_{r}}{\theta_{s}-\theta_{r}}\right)^{p}
$$

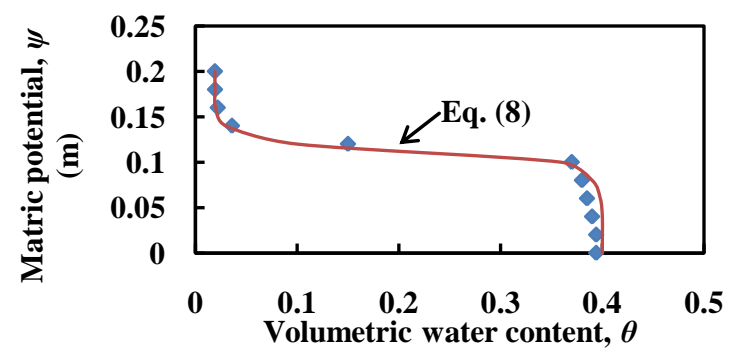

Fig. 3 Soil water retention curve of Kawanishi sand

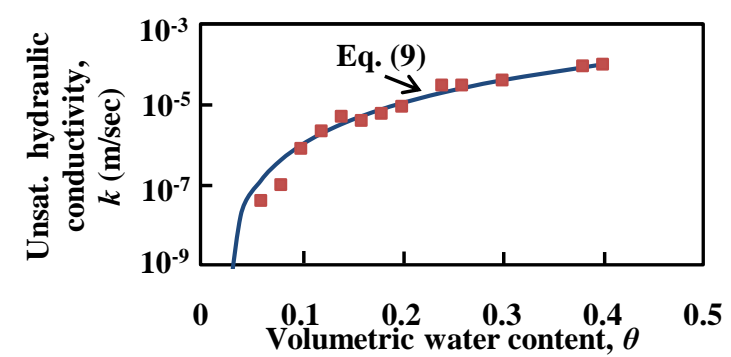

Fig. 4 Relation between unsaturated hydraulic conductivity and volumetric water content where $k_{s}=1 \times 10^{-4} \mathrm{~m} / \mathrm{sec}$ and $p$ is the curve index (=3).

\section{(2) Interfacial resistance coefficient}

Fig. 5 shows the relation between $M_{h s u p}$ and $P_{n}$. $M_{\text {hsup }}$ was given for the first four hours of the experiment. $M_{h s u p}$ is proportional to $P_{n}$ linearly like the regression line in Fig. 5.

$$
M_{\text {hsup }}=0.036 P_{n}+0.005
$$

Comparing Eq. (10) and Eq. (3), the value of $c$ became 1. It is inferred that the pore size of the interface may be the same size as the pore size in soil and that preferential water flow pathways can be ignored at the interface.

\section{(3) Evaporability test results}

The values of $\alpha_{v}$ and $\beta$ were obtained from the evaporability test and from the following assumptions. The external conditions of the present experiments were steady and the same for every experimental case. The soil surface temperature was also might be constant because $m_{\text {heva }}$ and $A_{\text {wet }}$ were very small. Therefore, $\alpha_{v}, D_{a t m}, \rho_{v s}$ and $\rho_{\text {vair }}$ in Eq. (5) might be constant and the same for every experimental case. The values of $\rho_{v s}, \rho_{\text {vair }}$ and $D_{\text {atm }}$ were calculated according to the equations expressed by Geraminegad et al. ${ }^{13)}$. $\alpha_{v}$ was obtained $274 \mathrm{~m}^{-1}$ from $m_{\text {heva }}$ during the constant evaporation period $(\theta$ $>0.06)$. The $\beta-\theta$ relation was obtained from $m_{\text {heva }}$ during the falling rate evaporation period and expressed as follows (see Fig. 6):

$$
\begin{array}{cr}
\beta=0 & (\theta \leq 0.02) \\
\beta=25 \theta-0.5 & (0.02<\theta \leq 0.06) \\
\beta=1 \quad(\theta>0.06)
\end{array}
$$

From the above $\beta-\theta$ relation, $\theta_{c r}=0.02$ was adopted for Kawanishi sand.

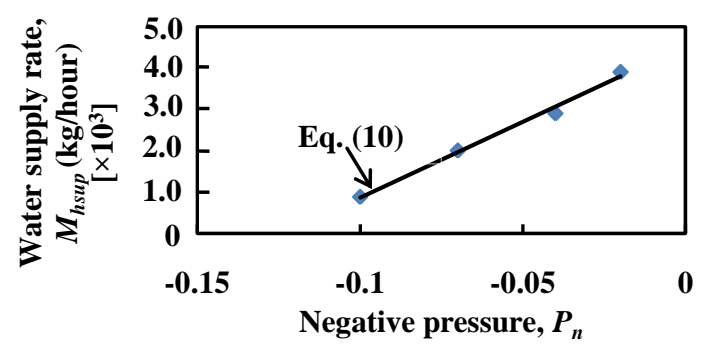

Fig. 5 Relation between water supply rate and negative pressure

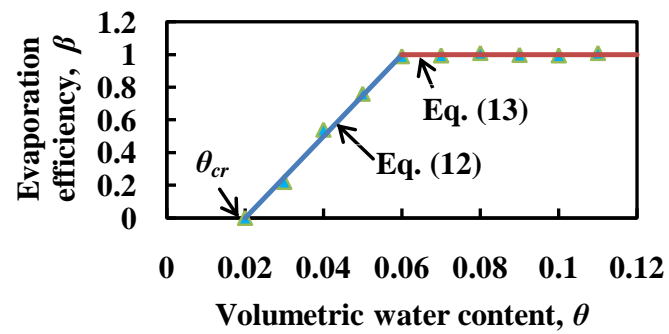

Fig. 6 Relation between evaporation efficiency and volumetric water content 

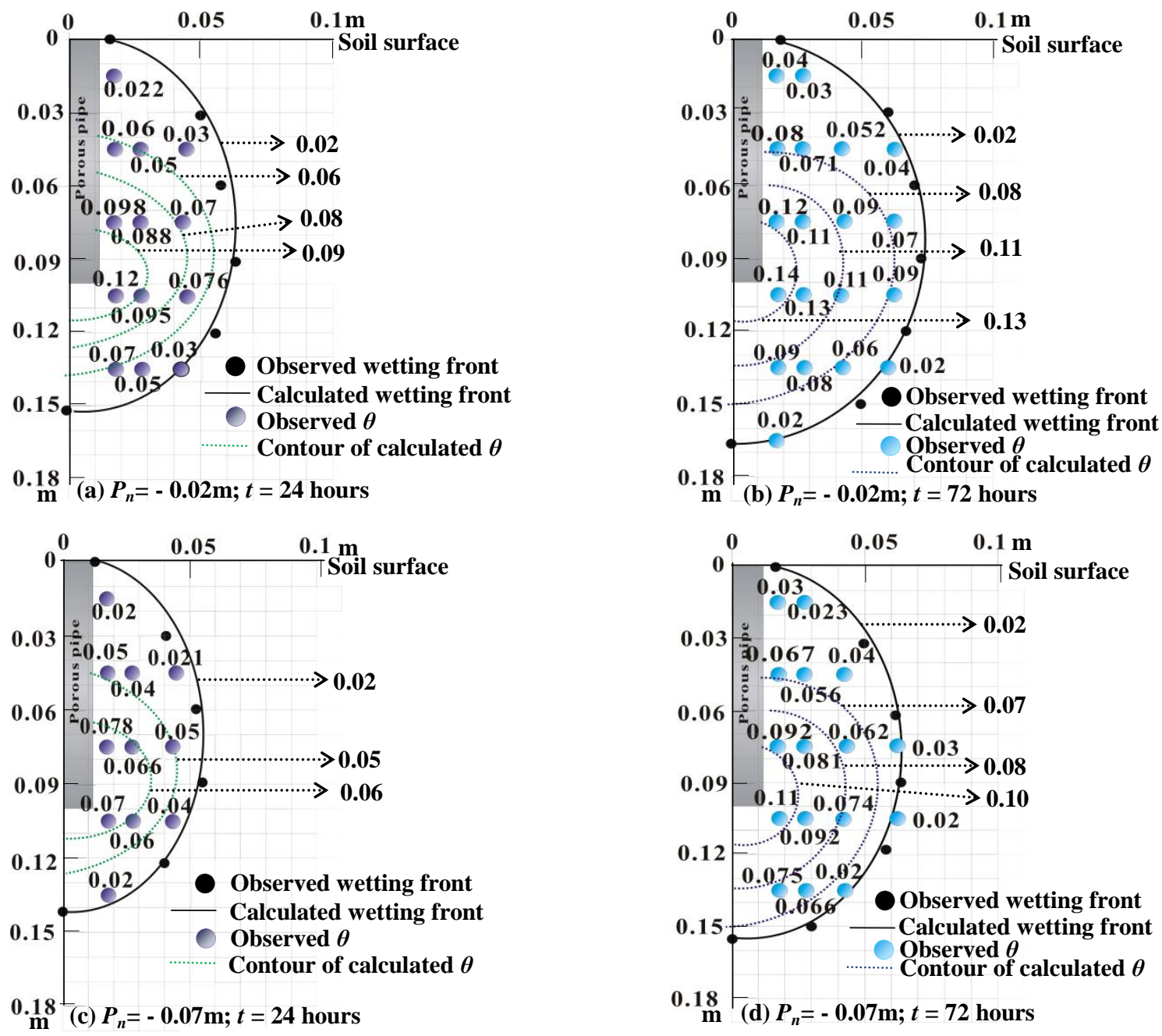

Fig. 7 Soil moisture content profiles and wetting fronts

\section{(4) Soil moisture content and wetted surface area}

Fig. 7 (a) through (d) show two dimensional counter plots of the measured $\theta$, the contour lines of the calculated $\theta$ and wetting fronts at $t=24$ and 72 hours for $P_{n}=-0.02$ and $-0.07 \mathrm{~m}$, respectively. The observed and calculated wetting fronts are also shown in these figures. The expansion of the wetting front became larger as $\left|P_{n}\right|$ decreased at the same $t$. The vertical expansion was more extensive than the radial one. The maximum radial and vertical expansion increased as $\left|P_{n}\right|$ decreased. When $\theta_{c r}$ was 0.02 , the observed wetting front corresponded well with the results of the calculation model.

Fig. 8 shows the temporal variations in observed and calculated $A_{\text {wet }}$ for $P_{n}=-0.02$ and $-0.07 \mathrm{~m}$. Both $A_{\text {wet }}$ were in good agreement each other. The commencement time of $A_{w e t}$ was assumed equal to the time $t_{i c}$ when $\theta$ of soil at the surface reached $\theta_{c r}$. The calculated $A_{\text {wet }}$ increased rapidly and then the increase in $A_{\text {wet }}$ slowed down.

\section{(5) Water balance}

Fig. 9 (a) and (b) show the temporal variations in the water balance described by Eq. (6) for $P_{n}=-0.02$ and $-0.07 \mathrm{~m}$, respectively. The symbols in the figures represent the measured values of $M_{\text {sup }}, M_{\text {soil }}$ and $M_{\text {eva }}$ and the solid lines show the calculated values explained as below.

$M_{\text {eva }}$ was calculated by the combination of Eqs. (4) and (5) for $t \geq t_{i c}$

$M_{\text {sup }}$ was calculated by the following integration: $M_{\text {sup }}=\int M_{\text {hsup }} d t . M_{\text {hsup }}$ was calculated by Eq. (1).

$M_{\text {soil }}$ was obtained by the integration of $\theta$ over the wetted soil volume in the column, $V_{\text {wet }}$, i.e. $M_{\text {soil }}=\rho_{w}$ $\int_{V \text { wet }} \theta d v$, where $v$ is the soil volume.

The calculated $M_{\text {sup }}, M_{\text {soil }}$ and $M_{\text {eva }}$ and the observed ones show good agreement over the experiment.

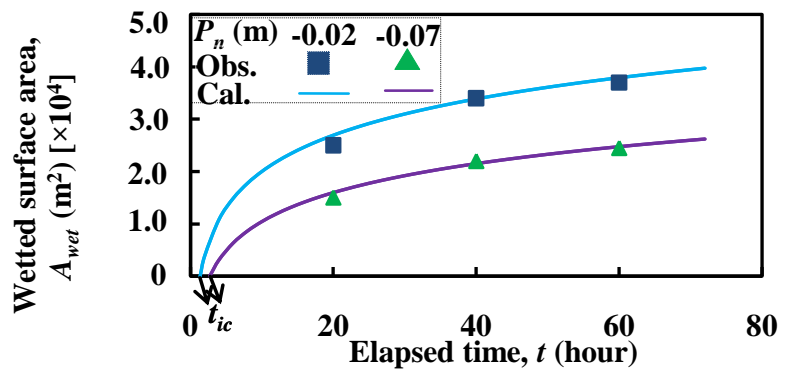

Fig. 8 Temporal variations in wetted surface area 

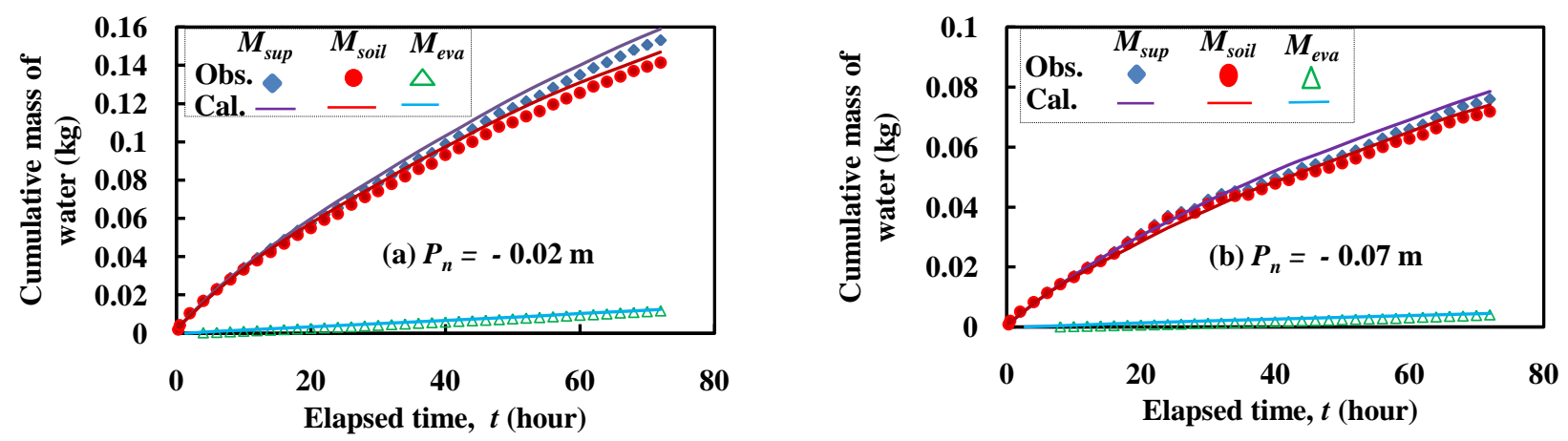

Fig. 9 Comparison of observed and calculated temporal variations in water balance

Table 1 Water balance accuracy at the end of experiment

\begin{tabular}{|c|c|c|c|c|}
\hline $\begin{array}{c}P_{n} \\
(\mathrm{~m})\end{array}$ & Components & $\begin{array}{c}\text { Observed } \\
(\mathrm{kg})\end{array}$ & $\begin{array}{c}\text { Calculated } \\
(\mathrm{kg})\end{array}$ & $\begin{array}{c}\text { Error } \\
(\%)\end{array}$ \\
\hline \hline \multirow{3}{*}{0.02} & $M_{\text {sup }}$ & 0.1531 & 0.1590 & 3.9 \\
\cline { 2 - 5 } & $M_{\text {soil }}$ & 0.1414 & 0.1470 & 4.0 \\
\cline { 2 - 5 } & $M_{\text {eva }}$ & 0.0117 & 0.0124 & 6.0 \\
\hline \multirow{3}{*}{-0.07} & $M_{\text {sup }}$ & 0.0759 & 0.0785 & 3.4 \\
\cline { 2 - 5 } & $M_{\text {soil }}$ & 0.0718 & 0.0740 & 3.1 \\
\cline { 2 - 5 } & $M_{\text {eva }}$ & 0.0041 & 0.0044 & 7.3 \\
\hline
\end{tabular}

Table 1 describes the water balance accuracy at the end of the experiment. The margin of error was in the range of 3 to $7 \%$.

\section{CONCLUSIONS}

A theoretical model to predict the water balance and soil wetting pattern in the negative pressure difference irrigation (NPDI) system was proposed in this paper. Laboratory experiments were carried out to support the validity of the proposed theoretical model using a porous pipe, a water reservoir, and a soil column filled with Kawanishi sand. The main conclusions drawn from the present study are as follows:

1) The temporal variations of the volumetric water content profile, evaporation, soil water storage and supplied water calculated by the proposed model are in good agreement with the experimental results.

2) The interfacial resistance coefficient is 1 .

3) The critical volumetric water content is 0.02 for Kawanishi sand.

4) The margin of error in the water balance is in the range of 3 to $7 \%$.

5) The proposed model is valid for an optimal design of the NPDI system.

\section{REFERENCES}

1) Yabe, K., Kato, Z. and Tejima, S.: Disparities of water management in the sub-irrigation method by negative pressure difference and the drip irrigation method, Trans. JSIDRE, vol.123, pp.11-16, Jun. 1986.

2) Kato, Z., and Tejima, S. : Theory and fundamental studies on subsurface irrigation method by use of negative pressure, Trans. JSIDRE, vol.101, pp.46-54, Oct. 1982.

3) Tanigawa, T., Yabe, K. and Tejima, S.: Comparison of prediction of actual measurement about dynamic distribution of soil moisture tension, Trans. JSIDRE, vol.137, pp.9-16, Oct. 1988.

4) Ashrafi, S., Gupta, A. D., Babel, M. S., Izumi, N. and Loof, R.: Simulation of infiltration from porous clay pipe in subsurface irrigtion, Hydrological Sciences-Journal, vol.47(2), pp.253-268, Apr. 2002.

5) Siyal, A. A. and Skaggs, T. H.: Measured and simulated soil wetting patterns under porous clay pipe sub-surface irrigation, J. of Agricultural Water Management, vol.96, pp.893-904, 2009.

6) Peifu, J., Lei, T., Xiao, J., Yu, Y. and Bralts, V. F.: A new irrigation system of zero/ negative pressure and the experimental verification of its feasibility, ASAE/CSAE Annual International Meeting Presentation, paper no. 042253, Ontario, Canada, August, 2004.

7) Akhoond, A. M. and Golabi, M.: Subsurface porous pipe irrigation with vertical option as a suitable irrigation method for light soils, Asian J. of Scientific Research, vol.1(3), pp. 180-192, 2008.

8) Futagami, S., Takano, Y., Fukuhara, T. and Sato, K.: Heat and moisture transfer between sand surface and atmosphere by surface layer model - consideration of thickness of sand surface layer by $\alpha-\beta$ method, Ann. J. of Hydraulic Engineering, vol. 41, pp. 37-42, 1997.

9) Fukuhara, T. and Islam, M. S.: Heat transfer model of horizontal u-tube (HUT) road heating system, A Dr. of Eng. Thesis Supervised by Fukuhara and Submitted by Islam to the University of Fukui, Japan, 2007.

10) Kono, I. and Nishigaki, M.: An experimental study on characteristics of seepage through unsaturated sandy soil, $J$. of Japan soc. of Civil Eng., vol.307, pp. 59-67, 1981.

11) Van Genuchten M. T.: A closed form equation for predicting the hydraulic conductivity of unsaturated soils, Soil Sci. Soc. Am. J., vol. 44, pp. 892-898, 1980.

12) Brooks, R. J. and Corey, A. T.: Hydraulic properties of porous media, Hydrol.Pap.3 Colo. State Univ., Fort Collins, 1964.

13) Geraminegad, M. A. and Saxena, S. K.: A solution of coupled heat-moisture transfer in saturated-unsaturated media, Proc. $5^{\text {th }}$ International Conference on Numerical Method, pp. 567 - 574, Nagoya, 1985.

(Received September 30, 2010) 